\section{$\underset{\substack{\text { hommes } \\ \text { \& migrations }}}{ }$}

\section{Hommes \& migrations}

Revue française de référence sur les dynamiques

migratoires

$1297 \mid 2012$

Migrations en création

\title{
Migrations en création
}

\section{Marie Poinsot}

\section{CpenEdition \\ Journals}

\section{Édition électronique}

URL : http://journals.openedition.org/hommesmigrations/1291

DOI : 10.4000/hommesmigrations. 1291

ISSN : 2262-3353

\section{Éditeur}

Musée national de l'histoire de l'immigration

Édition imprimée

Date de publication : 1 mai 2012

Pagination : $\mathrm{fr}$

ISSN : 1142-852X

Référence électronique

Marie Poinsot, « Migrations en création », Hommes \& migrations [En ligne], 1297 | 2012, mis en ligne le 29 mai 2013, consulté le 22 septembre 2020. URL : http://journals.openedition.org/

hommesmigrations/1291 ; DOI : https://doi.org/10.4000/hommesmigrations.1291 


\title{
Migrations en création
}

\author{
Par Marie Poinsot, rédactrice en chef
}

\begin{abstract}
À l'occasion de l'exposition J'ai deux amours présentée par la Cité nationale de l'histoire de l'immigration, Hommes \& Migrations a envisagé de publier un dossier consacré aux représentations des phénomènes migratoires à travers les créations contemporaines. La Cité innove en décidant de faire coexister des collections d'œuvres d'art contemporaines à côté des collections historiques et anthropologiques qui relèvent généralement de la mission des musées de société. Intriguée par cette approche avant-gardiste, la revue s'est mise au service d'une réflexion plus large sur le sens de cette émergence des problématiques migratoires dans le domaine artistique.
\end{abstract}

Ce dossier, fruit d'un appel à contribution, fait état de plusieurs travaux menés dans le champ de l'histoire culturelle ou de la sociologie de l'art associé aux problématiques migratoires qui constituent aujourd'hui de nouveaux chantiers de recherches. Deux entrées thématiques complémentaires sont explorées. D'une part, l'analyse des expressions artistiques qui prennent comme problématique les réalités migratoires, qu'elles soient issues d'artistes d'origine étrangère ou non. Histoires vécues, dénonciations, reconnaissance ou engagement, toutes les expressions artistiques sont analysées en montrant la diversité des démarches et des œuvres.

D'autre part, les représentations des migrations ou de l'autre perçu comme étranger, exilé, migrant, et qui sont inscrites dans les productions artistiques contemporaine. Ainsi, les relations de l'art avec les dynamiques culturelles et sociales issues des migrations sont décrites pour nous faire comprendre pourquoi les phénomènes migratoires sont devenus un des enjeux de la scène artistique mondiale. II s'avère que les migrations dynamisent une création occidentale quelque peu essoufflée en introduisant des thèmes fondamentaux comme le rapport à l'altérité, les mobilités humaines, les mutations des modèles culturels, etc. Ces thèmes venus de l'extérieur font désormais partie intégrante des questionnements internes au champ artistique.

On observe le passage d'un art postcolonial à un art transnational jouant avec les frontières, les identités, les enracinements, ou s'en jouant, pour libérer les expressions individuelles ou collectives (en tant que porte-parole de populations marginalisées), et capable de faire émerger des questionnements sur les codes esthétiques dans toutes les disciplines artistiques.

Ce dossier a noué un partenariat avec la Fondation européenne pour la culture à l'occasion du séminaire qui s'est tenu à la Cité nationale de l'histoire de l'immigration en décembre 2011 sur les dynamiques qui concourent à la conception et à la mise en forme de récits sur l'Europe de la part d'artistes venus d'ailleurs.

La revue est heureuse d'accueillir dans ses colonnes les résultats de ce séminaire. Elle a pu bénéficier du soutien de la Fondation pour illustrer certains articles avec les photographies d'Ad van Denderen, un des fleurons de la collection de la Cité, qui a accepté qu'on reproduise ses œuvres dans ce numéro. Qu'ils en soient tous chaleureusement remerciés. 